\title{
Review Article: Different Types of Coronal Restoration for Endodontically Treated Anterior Teeth: Treatment Recommendation
}

\author{
Samsudin Nurulaqmar-Iwani, DDS* \\ Trainee Lecturer (Conservative), School of Dental Sciences, Universiti Sains Malaysia, Health \\ Campus Universiti Sains Malaysia,16150 Kubang Kerian Kelantan, Malaysia \\ *Corresponding Author: Samsudin Nurulaqmar-Iwani, DDS, Trainee Lecturer (Conservative), School \\ of Dental Sciences,Universiti Sains Malaysia, Health Campus Universiti Sains Malaysia,16150 \\ Kubang Kerian Kelantan, Malaysia
}

\begin{abstract}
An adequate coronal restoration after completion of endodontic treatment is an integral part of restorative dentistry. Most failure cases of endodontically treated teeth are due to an inadequate or poor coronal seal or restoration, even though they have achieved a thorough and adequate cleaning of the canals. Failure to construct an excellent coronal seal after an endodontic treatment will lead to persistent microleakage from the oral cavity into the filled canal. Anterior teeth which have undergone endodontic treatment may need a material which not only offers an excellent coronal seal but also to achieve a maximum aesthetic appearance.
\end{abstract}

There are multiple suitable types of material which vary from preparation techniques and procedures. Most endodontically treated anterior teeth can be restored conservatively with bonded restoration; however, some prefer to have a full fix crown prosthesis for the teeth

Clinical Relevance: Aesthetic restoration of anterior teeth is extremely important. There are many situations the selection of coronal restoration after endodontic treatment would affect the aesthetic result.

Objective: To discuss the materials, types and techniques among the choices available for the restoration of endodontically treated anterior teeth.

Keywords: Endodontically treated teeth, coronal seal, coronal restoration,

\section{INTRODUCTION}

Previous studies have revealed that the endodontically treated teeth (ETT) are more brittle due to loss of structural integrity associated with canal preparation or caries remova [1]. When comparing the ETT with the vital teeth, studies have shown that fractures are more common in ETT due to water loss (10\%) [2]. However, micro hardness, elastic modulus, and tensile/compression strength show no significant differences. Furthermore, access cavity preparation may reduce fracture resistance due to an increase in the tapering size of the canal, but has no significant effect in terms of conservative or traditional access cavity preparation [3]. The loss of both coronal and radicular tooth structures as a result of the endodontic treatment will increase the likelihood of fractures during functional loading. Endodontic procedures are responsible for $38 \%$ of the reduction in flexural strength of crowns [4]. Another study comparing the fracture resistance between ETT of anterior teeth against sound similar teeth with various restorative techniques found that ETTs were generally weaker than their intact sound counterparts [5]. Some studies have examined the survival distribution of primary root canal treatment and factors affecting the outcomes of ETT. The longevity of ETT as based on survival affected by a few factors includingsociodemographic, pre-, intra-, and post-operative factors [6]. Timely placement of a definitive restoration improves the tooth survival and the outcomes of ETT [7]. The lack of a permanent restoration dramatically decreases survival rates of ETT [8]. Anterior teeth with a minimal loss of tooth structure due to endodontic procedures can be restored conservatively with bonded restoration to preserve the coronal and radicular tooth structure [9]. The use of materials that can bond directly to the dentine is always an alternative option for the reconstruction and rehabilitation of endodontic ally treated teeth [10]. 
Review Article: Different Types of Coronal Restoration for Endodontically Treated Anterior Teeth: Treatment Recommendation

\section{RESTORATION TYPE FOR THE ANTERIOR TEETH}

Once the completed endodontic treatment has been achieved to a technically satisfactory standard and the tooth itself is asymptomatic, it is feasible to proceed with the final restoration just immediately after the satisfaction result of root canal obturation. This is particularly true when dealing with a previously vital, uninfected tooth[11]According to Huumonen $S$ et al,teeth with initially healthy periapical structures predictably maintain good periapical health, and healing of pre-existing periapical lesions is most pronounced from three months to two years [12]. Endodontic outcomes are driven by the presence of preoperative root canal infection (apical periodontitis) and anterior teeth are more likely to be restored with a filling sooner than the posterior teeth[13]. The type of final restoration for an ETT anterior tooth is determined by the amount of remaining tooth structure. Pratt et alrevealed that teeth that

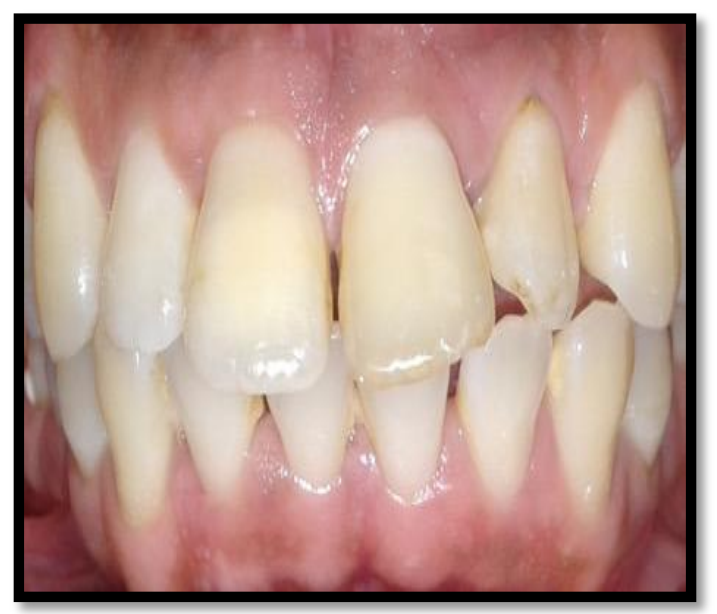

Figure1a. Necrotic 11, 21 and 22 with an intact coronal structure received a crown four months after RCT were almost three times more likely to get extracted compared with teeth that received crown within four months of RCT. The most common reasons for the extraction of ETT after RCT were crown fractures $(60 \%)$, restoration failures $(20 \%)$, endodontic reasons (7.6\%), and unknown reasons (12.4\%) [14].

Pereira et al compared the resistance of ETT with an intra-radicular retainer for the different amounts of remaining coronal structure and the results of this study showed that there were no significant differences among the groups with remaining coronal structure in between $1 \mathrm{~mm}, 2$ $\mathrm{mm}$ and $3 \mathrm{~mm}$. When the dental crown was not completely removed, the amount of remaining coronal dentin did not significantly affect the fracture strength of endodontically treated teeth with an intra-radicular retainer [15]. Figure 1 shows an example of RCT anterior teeth without no indication for the invasive tooth structure preparation for post core crown placement.

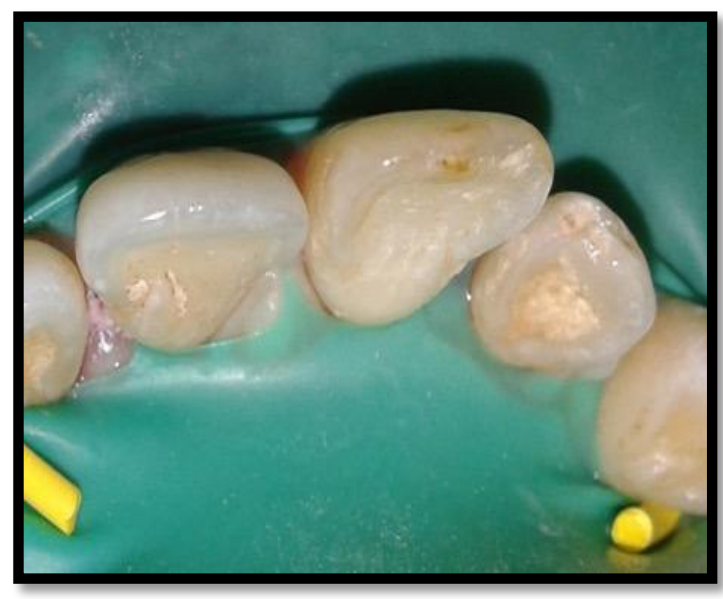

Figure1b. Teeth under rubber dam isolation prior to the RCT. Most of the palatal structure were also in intact.

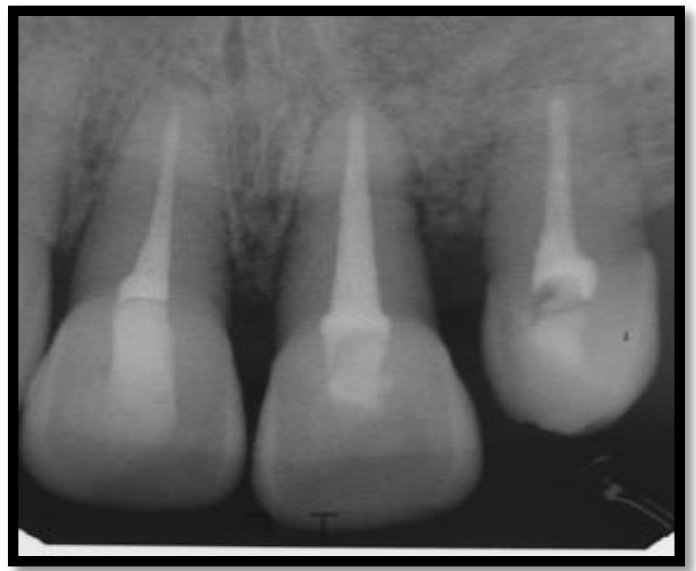

Figure1c. Periapical radiograph of obturated anterior teeth. More than 50\% of the tooth structure remains.

According to Ratnakar et al, the author considers conservative treatment in a form of composite resin, glass ionomer, or amalgam restorations (for the posterior teeth) with 
Review Article: Different Types of Coronal Restoration for Endodontically Treated Anterior Teeth: Treatment Recommendation

minimal coronal damage. When a tooth has more than $50 \%$ of the coronal structure missing, the use of post and core foundation is recommended[16]. Postinsertion in anterior teeth with minimal coronal tooth structure remaining can provide resistance against tipping or lateral forces and contribute to form aretention.

\section{COMPOSITE RESIN RESTORATION}

Most anterior teeth with intact coronal structure can be restored using direct composite resin restorations. Anterior ETT with cavity access confined at the lingual site does not require complete coverage crowns, except when structurally weakened by large or multiple coronal restorations[9]. Direct composite resin restorations were the materials of choice because of the satisfactory aesthetics and minimal wear of the opposing tooth structure. They are available in a wide variety of colors, and allow combinations of translucency and opacity of dental structures. Zimmerli et al. and Gaiao et al. reported that the use of resins that do not use the VITA shade guide scale is easy to understand and allows a simplified application of the restorative system in a predictable, fast, and efficient way to improve the aesthetics of anterior teeth. The VITA classical A1-D4®system is a basic solution that offers 16 natural tooth shades and one that has been internationally established for decades [17,18]. Restoration using direct composite resin is an excellent treatment option to conserve more tooth structure in ETT[19]. A similar fracture rate was observed in the influence of composite thickness (with or without fiber reinforcement) on fracture resistance of direct restorations in ETT [20]. Direct restoration with composite resin provides more resistance against tooth fracture than amalgam, as well as providing intra-coronal reinforcement [21]. Belli et al evaluated the fiber-reinforced composite resin restorations and concluded that using polyethylene fiber under composite restorations in root-filled teeth with MOD preparations significantly increases fracture strength, reduces leakage in class 2 cavities and strengthens micro tensile bonding to dentin [22]. These results are possibly applicable to the anterior teeth.

\section{Ceramic or Composite Resin Veneers}

Veneers usually cover the entire labial surface of the tooth, including the incisal edge and through to the proximal contacts. Ceramic or composite resin veneers are rarely recommended for ETT, as it is not easy to incorporate the access cavity within such restorations, and often the tooth tissue loss means a significant reduction in available surface area to bond to [23]. Shu et alstated that there was a weak recommendation of indirect restoration to restore ETT, especially for the teeth with extensive coronal damage [24]. However, veneer restorations appear more advantageous than a crown, as placement of glass fiber posts has no positive effect [25]. Bonded porcelain veneers offer several significant advantages over metal- ceramic and all- ceramic crowns[26]. One of the most important advantages is that they are extremely conservative in terms of tooth structure. Bonded veneers require only 0.2 to $0.5 \mathrm{~mm}$ reduction on the labial surface and usually none on the gingival two-thirds of the lingual surface [27]. Resin composite veneers can be used to mask tooth discolorations and/or to correct anesthetic tooth forms and positions, especially after being endodontic ally treated. Although composite resins are aesthetic and easy to manipulate, such restorations have limited longevity because of their undesired properties such as staining, micro leakage, low abrasion resistance, and plaque accumulation, while porcelain veneers have high abrasion resistance and color stability [28]. Porcelain veneers show excellent aesthetic results and predictable longevity of the treatment, while composite veneers can be considered as a good conservative option, but offer less durability [29].

\section{Metal Ceramic Crowns}

Metal ceramic crowns are indicated when an anterior, ETT is to be crowned and represent the main nonadhesive restoration of the anterior dentition. Tooth preparation for metal- ceramic crowns has been reported in the dental literature, and it is accepted that finish line configuration and position concerning gingival tissue can influence longevity and aesthetic of final restoration. According to Shillingburg et al the minimum thickness of porcelain and metal required for metal-ceramic crowns, dependent on the alloy used, is 0.7 and $0.5 \mathrm{~mm}$, respectively, it is accepted that a labial reduction of $1.5 \mathrm{~mm}$ is required[30]. Clinicians are sensible to consider full metal coverage on the palatal surface to minimize the reduction in the area, thus increasing-cosmetic consideration. Ram et al evaluated three tooth preparation techniques for metal- ceramic crown by comparing preparation depth. The result from the study showed the mean depth of labial and incisal preparation for Groups A, B and C were 
1.23 and $1.72 \mathrm{~mm}, 1.45$ and $1.96 \mathrm{~mm}$, and 1.47 and $1.95 \mathrm{~mm}$, respectively and the mean palatal preparation was $0.46 \mathrm{~mm}$ for Group A, $0.54 \mathrm{~mm}$ for Group B and $0.59 \mathrm{~mm}$ for Group C [31]. Generally, fixed crown construction of ETT was indicated if the amount of tooth structure left is not sufficient for direct restoration. Due to their metal substructure, metal-ceramic crowns are the stronger type of restoration. Metalceramic crowns show success rate, and after 10 years, $95 \%$ of the metal-ceramic restorations are still present in the oral cavity [32]. The metalceramic group showed fracture resistance with a higher mean value $(1804.2 \pm 184.4)$ than the mean value of the CAD/CAM zirconia allceramic group (1353.4 \pm 95.3$)$ [33]. Besides the dentist may get challenges to achieve the most natural-looking results in metal-ceramic crown especially on anterior teeth hence the metal substructure must be masked by placing a layer of very opaque (chalky-white) porcelain over it [34].The clinician should precisely make a good clinical judgment before selecting the metalceramic crowns.

\section{All Ceramic Crowns}

All-ceramic crowns are restorations in which full thickness is made entirely of a glass-like substance, such as porcelain, and offer superior aesthetics to the patient because the entire thickness of the crown is $100 \%$ ceramic. The evolution of ceramic technology in dental CAD/CAM systems has enhanced the options to produce single all -ceramic endo-crowns with high biocompatibility and optimal mechanical properties [33, 35]. The custom shaping and precise milling of ceramic restorations are now a reality; furthermore. the adaptation of the inner surface of the restoration and the replication of the occlusal morphology is better. While

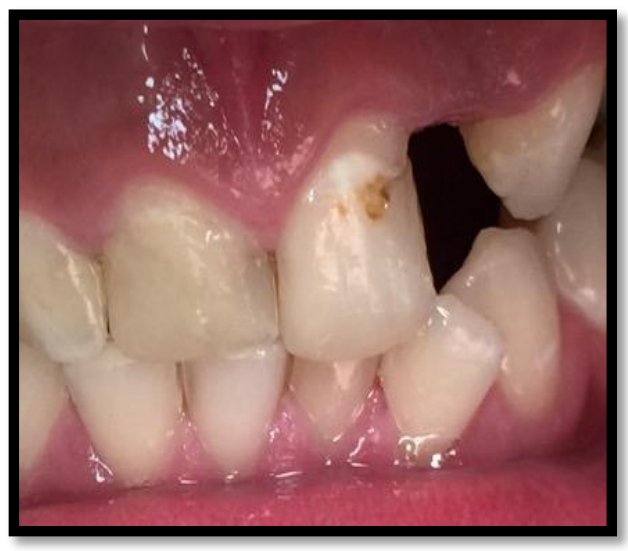

Figure 2a. Tooth 11 and 21 indicate for RCT relatively rare, some people are allergic to some of the component metals found in the various types of alloys. Metals used in dentistry can lead to metal sensitization and the sensitization rates of metals differ [36]. A comparative study exhibited clear evidence that sensitization to certain dental metals, including $\mathrm{Ni}$ and $\mathrm{Co}$, can be identified by a patch test before implantation, thus guiding dental clinicians in the selection of prosthodontic material [37]. Therefore, allceramic crowns are the best choice. Some types of ceramics have substantially inferior physical characteristics in terms of strength, hardness, brittleness, and resistance to fracture compare to the metal crown and porcelain fused to metal (PFM)[33]. However, based on the systematic review, all-ceramic crowns, for anterior teeth, showed survival rates at 5 years compared to those seen for metal-ceramic crowns [38]. Carlos et al. reported that endo-crown constructed with either ceramic system (pressable ceramic systems) or computer- aided design/ computer- aided manufacturing (CAD/CAM) systems showed no aesthetic and functional degradation [39].Similar results were reported by Lazicet al in which a 12-month follow up of two Cerec and Emoress endo-crowns showed satisfactory behaviorin terms of aesthetics, restoration stability, and tissue preservation [35]. Besides, Hamdy et al revealed that groups with full coverage allceramic restoration, intact teeth and all-ceramic endo-crown restoration showed the highest fracture resistance, with no significant differences between them [40].

Figure 2 shows an indication for the RCT of 21 for all-ceramic crown. Post placement is indicated since the tooth is going to be an abutment for bridge construction to replace missing 22

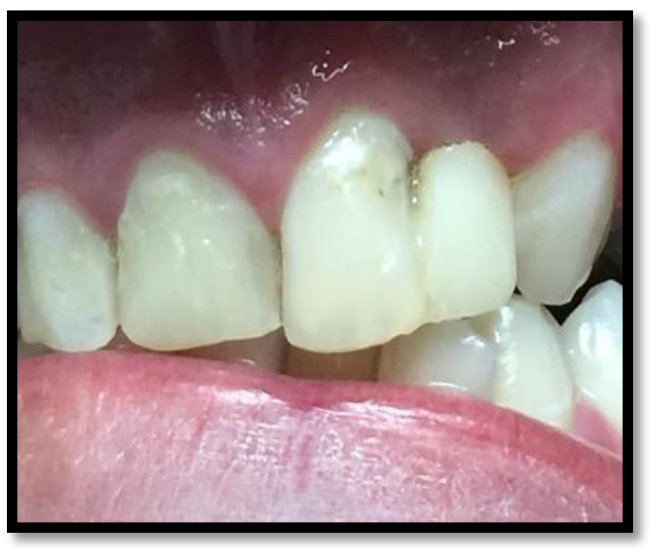

Figure 2b. Temporary bridge for tooth 22. Postplacement needs for tooth 21 since it is going to be an abutment for a bridge construction 
Review Article: Different Types of Coronal Restoration for Endodontically Treated Anterior Teeth: Treatment Recommendation

\section{Post Placement and Restoration}

The placement of a post is indicated for ETT, which needs a crown when the amount of residual tooth structure is not sufficient to support a core composite. The primary purpose of a post is to retain a core in a tooth with extensive loss of coronal tooth structure[41].A clinical study showed that the success rate of endodontically treated premolar restored with fiber post and direct composite restorations after three years of service were equivalent to a similar treatment of full coverage with metal crown[19]. Naumann et al emphasize that it was critical to consider both the number of remaining cavity walls and tooth type when placing posts, particularly in teeth with three to four remaining coronal walls, which may be considered as overtreatment [42]. Cheung et al showed that the amount of remaining coronal tooth structure and the functional requirements of the tooth determine either indication or contraindication for post placement [43]. Pruthi et alshowed parallel posts to have better retention than tapered and double tapered posts [44]. Regarding the fracture resistance, double tapered posts were found to be better than parallel and tapered posts. According to Schwartz \& Robbins, the original purpose of a post is only to retain the core and not to increase the intrinsic resistance of the root[45]. Studies also demonstrated that the use of posts did not influence the fatigue resistance of posterior teeth and neither did in anterior teeth with ferrule [38, 46]. The retention of a post depends on its shape, size, and post length. For adequate retention of a post, its length should be equal to or larger than the crown length [45]. The influence of the amount of remaining tooth structure on the fracture resistance of ETT has been frequently emphasized [47-50]. The strength of fiberreinforced posts to be lower than that of metal posts [51]. However, increasing the diameter of the fiber posts makes it stiffer and more resistant to fracture. The classic cast post and core design with a $2 \mathrm{~mm}$ ferrule design offer superior resistance than the core design with the encirclement of the tooth ferrule, although the results were not statistically significant[52].The retention of passive posts relies mostly on the cement used for luting, especially in the case of tapered posts. It has been demonstrated that resinbased types of cement have greater bond strength than conventional types of cement such as zinc phosphate[45]

Since a post does not strengthen an ETT and the preparation of a post space may increase the risk of root fracture and treatment failure, the decision to use a post in any clinical situation must be made judiciously [53].

\section{TyPE OF POST}

In general, Post and Core (PC) systems can be divided into two categories: casting and prefabricated. Prefabricated posts can be made of metal or tooth-colored materials[54] Rosenstiel $\mathrm{SF}$, et al. stated that both cast and prefabricated post cores generally offer the same expected survival rates and suggestionthat placing a prefabricated postcan make a good choice in most situations. Prefabricated posts are typically made of stainless steel, nickel- chromium alloy, or titanium alloy. Passive, tapered posts offer the least retention of the prefabricated posts but allow minimal removal of radicular dentin because their tapered shape resembles the overall canal morphology [55]. Additional retention can be gained with a parallel postby the use of resin cement, or by the use of an active post [56].

Cast gold PC is considered the gold standard because of a high success rate. However, failure to achieve the desired aesthetics is a major problem encountered upon using cast metal systems [57]. For anterior ETT, the use of toothcolored posts such as ceramic posts and fiberreinforced composite (FRC) posts, is common because of better aesthetic results. Besides ceramic posts demonstrate high strength and hardness, while fiberglass posts show a lower strength and a higher elasticity [58].

\section{Fiber Post}

Fiber posts were introduced as aesthetic posts because of their excellent aesthetic result. The specific needs of light, translucent composite resins, and ceramics to mimic the natural tooth required the use of translucent posts in the aesthetic zone of anterior region, usually required fiber post because of the metal post can cause shadowing of the soft tissues adjacent to the root surface that will compromise aesthetic result [25]. Fiber-reinforced posts are fabricated to bond with most resin cement and resin-based composite core materials. Instead of blackish carbon type of post, different posts that give more aesthetic color including quartz fiber, glass fiber, and silicon fiber. They we reclaimed to have the same advantages as the carbon fiber posts, with a better appearance. King et al revealed the favorable results in terms of 
Review Article: Different Types of Coronal Restoration for Endodontically Treated Anterior Teeth: Treatment Recommendation

fracture resistance for both Carbon Fiber Reinforce Carbon (CFRC,) a reinforced version of carbon fiber, and conventional cast posts [59].

Fiber- reinforced composite (FRC) posts have a higher flexural strength than metal post and zirconia posts. The modulus of elasticity of these posts is close to that of dentin; therefore, they can create a single-unit bonding with the tooth, and they absorb most of the stress, leading to limited stress distribution in the remaining tooth structure [60]. Rosentritt et alconcluded that the teeth restored with fiber posts have a lower fracture strength in comparison with those restored by using metal posts [61]. Four years of clinical performance in ETT restored with either carbon fiber post or cast post showed that the ideal post should have amodulus of elasticity and carbon fiber posts fulfilled this requirement[47]. Guragain, Mathema \& Rokaya found that aglass fiber post, indirect resin post, and prefabricated metal post with resin core and indirect resin crown systems showed statistically insignificant fracture strength values and modes of failure [62]. The survival rate of different post types in maintaining an excellent coronal seal is dependent on the direct placement of a post and core at the time of completion of the root canal treatment, followed by the provision of a temporary crown, as shown in Table1[63]. Whereas Table 2 presented some advantages, disadvantages, and indications of different post and core to be used in endodontically anterior teeth [62].

Table 1

\begin{tabular}{|l|l|l|}
\hline Table 1:Outcome of the Post & Type of Post & Survival rate \\
\hline Study & Cast post and cores & $99 \%$ at 10 years \\
\hline Weine 1991 & Cast post and cores & $82 \%$ at 10 years \\
\hline Mentink 1993 & Screw post and composite & $75-87 \%$ at 6 years \\
\hline Creuger (meta-analysis)1993 & Cast post and cores & $88-94 \%$ at 6 years \\
\hline Jung 2007 & Titanium posts and composite & $93.5 \%$ at 8.5 years \\
& build ups Case post and cores & $90.2 \%$ at 8.5 years \\
\hline Signore 2009 & Glass fibre posts and all ceramic & $98 \%$ at 8 years (root fracture) \\
\hline Tidehag 2004 & crowns & \\
\hline Segerstrom 2006 & Carbon fibre posts & $90 \%$ at 7 years \\
\hline Nauman 2005 & Carbon fibre posts & $65 \%$ at 6.7 years \\
\hline
\end{tabular}

Table2. Advantages, disadvantages, and indications of different posts and cores

\begin{tabular}{|l|l|l|l|}
\hline Post systems & Glass fibre & Indirect resin & Prefabricated metal \\
\hline Indication & $\begin{array}{l}\text { Indicated when high } \\
\text { aesthetic is required }\end{array}$ & $\begin{array}{l}\text { Useful teeth without loss } \\
\text { of tooth structure }\end{array}$ & $\begin{array}{l}\text { Useful for grossly } \\
\text { decayed teeth and high } \\
\text { strength is required }\end{array}$ \\
\hline Advantages & $\begin{array}{l}\bullet \text { Aesthetic } \\
\bullet \text { Moderate fracture } \\
\text { resistance } \\
\bullet \text { Removability }\end{array}$ & $\begin{array}{l}\bullet \text { Moderate aesthetic } \\
\text { - Better fitting }\end{array}$ & $\begin{array}{l}\text { High strength } \\
\bullet \text { Maximum fracture } \\
\text { resistance } \\
\text { Removability }\end{array}$ \\
\hline Disadvantages & $\bullet$ Mostly radiopaque & $\begin{array}{l}\bullet \text { Least indirect resin } \\
\text { dowel and post }\end{array}$ & $\begin{array}{l}\text { - Least aesthetic } \\
\text { Radiopaque }\end{array}$ \\
\hline
\end{tabular}

(Guragain, Mathema \& Rokaya, 2020)

\section{CONCLUSION}

The coronal restoration of ETT of anterior teeth is becoming an integral part of restorative dentistry. However,the evidence base is insufficient and each tooth will need individual assessment. It is a very demanding process and procedure in terms ofclarity when considering an ideal approach to restore ETT of anterior teeth. As a conclusion,I would suggest that the direct composite restoration is one of the best choices of treatment in restoring the ETT anteriorly but the prefabricated post and core with crown build-up still the choice of restoring the ETT with extensive loss of tooth structures. However,the clinicians must consider the biological need, long term prognosis, and the limitations of available materials in providing the best ideal coronal restoration of endodontically treated anterior teeth. 
Review Article: Different Types of Coronal Restoration for Endodontically Treated Anterior Teeth: Treatment Recommendation

\section{ACKNOWLEDGEMENTS}

I would like to express my profound gratitude to Dr Nik Rozainah binti Nik Abdul Ghani as senior Endodontist from Unit of Conservative Dentistry , School of Dental Sciences, Universiti Sains Malaysia for their continuous support, guidance and encouragement throughout my writing.

I am also most thankful to the Dean of School of Dental Sciences Universiti Sains Malaysia , Head of Department from Unit of Conservative Dentistry , School of Dental Sciences, Universiti Sains Malaysia and all my other senior colleques.

Finally, I would like to convey my sincere gratitude to my parents, my husband and my family for their support, understanding and love.

\section{REFERENCES}

[1] Faria, A. C. L., Rodrigues, R. C. S., de Almeida Antunes, R. P., et al. Endodontically treated teeth: Characteristics and considerations to restore them. Journal of Prosthodontic Research, 201155(2), 69-74.

[2] Helfer, A. R., Melnick, S. \& Schilder, H. Determination of the moisture content of vital and pulpless teeth. Oral Surgery, Oral Medicine, Oral Pathology. 1972 34(4), 661-670.

[3] Sabeti, M., Kazem, M., Dianat, O., Bahrololumi, N., Beglou, A., Rahimipour, K., Dehnavi, F. Impact of Access Cavity Design and Root Canal Taper on Fracture Resistance of Endodontically Treated Teeth: An Ex Vivo Investigation. Journal of Endodontics, 201844(9), 1402-1406.

[4] Hussain SK, McDonald A, Moles DR. In vitro study investigating the mass of tooth structure removed following endodontic and restorative procedures. J Prosthet Dent, 2007, 98(4): 260-269

[5] Christina Michael, M., Husein, A., Zaripah Wan Bakar, W. \& Sulaiman, E. Fracture resistance of endodontically treated teeth: an in vitro study. Archives of Orofacial Sciences, 2010 5(2), 36-41

[6] Lee, A. H. C., Cheung, G. S. P. \& Wong, M. C. M. Long-term outcome of primary non-surgical root canal treatment, Clinical Oral Investigations (2012) 1607-1617.

[7] Willershausen B, Tekyatan H, Krummenauer F, Briseno Marroquin B. Survival rate of endodontically treated teeth in relation to conservative vs post insertion techniques - a retrospective study. Eur J Med Res. 2005, 10:204-8.

[8] Nagasiri, R., Chitmongkolsuk, S. Long-term survival of endodontically treated molars without crown coverage: A retrospective cohort study. Journal of Prosthetic Dentistry, 2005 93(2), 164-170.

[9] Baba, N. Z., White, S. N., Bogen, G. Endodontic Prognosis:Clinical Guide for Optimal Treatment Outcome, 2017, 161-192

[10] Newman, M. P., Yaman, P., Dennison, J., Rafter, M. \& Billy, E. Fracture resistance of endodontically treated teeth restored with composite posts. Journal of Prosthetic Dentistry, 2003 89(4), 360-367

[11] Manfredi, M., Figini, L., Gagliani, M. \& Lodi, G. Single versus multiple visits for endodontic treatment of permanent teeth. Cochrane Database of Systematic Reviews, 2016

[12] Huumonen, S., Ørstavik, D. Radiographic follow-up of periapical status after endodontic treatment of teeth with and without apical periodontitis. Clinical Oral Investigations, 2018, 17(9), 2099-2104

[13] Lone, M. M., Khan, F. R., Lone, M. A. Evaluation of microleakage in single-rooted teeth obturated with thermoplasticized guttapercha using various endodontic sealers: An invitro study. Journal of the College of Physicians and Surgeons Pakistan, 2018, 28(5), 339-343.

[14] Pratt, I., Aminoshariae, A., Montagnese, et al, Eight-Year Retrospective Study of the Critical Time Lapse between Root Canal Completion and Crown Placement: Its Influence on the Survival of Endodontically Treated Teeth. Journal of Endodontics. 2016, 42(11), 15981603.

[15] Pereira, J. R., Neto, T. D. M., et al, Influence of the remaining coronal structure on the resistance of teeth with intraradicular retainer. Brazilian Dental Journal.,2005, 16(3), 197-201.

[16] Ratnakar, P., Bhosgi, R., Metta, et al, Survey on restoration of endodontically treated anterior teeth: a questionnaire based study. Journal of international oral health: International Society of Preventive and Community Dentistry, 2014, 6(6), 41-5.

[17] Zimmerli, Brigitte \& Strub, Matthias \& Kissling - Jeger, Franziska \& Stadler, Oliver \& Lussi, Adrian. Composite materials: Composition, properties and clinical applications. A literature review. Schweizer Monatsschrift für Zahnmedizin $=$ Revue mensuelle suisse d'odonto-stomatologie = Rivista mensile svizzera di odontologia $e$ stomatologia / SSO, 2010, 120. 972-86.

[18] Gaião, U., da Cunha, L. F., de Almeida Kintopp, C., Garcia, A. V., Gonzaga, C. C., Moro, A., \&Correr, G. M. Clinical Steps for Restoration of Fractured Anterior Teeth: Color Protocol with Non-VITA Scale. Case reports in dentistry, 2019, 1-8. 
Review Article: Different Types of Coronal Restoration for Endodontically Treated Anterior Teeth: Treatment Recommendation

[19] Mannocci, F., Bertelli, E., Sherriff, M., Watson, T. F. \& Pitt Ford, T. R. Three-year clinical comparison of survival of endodontically treated teeth restored with either full cast coverage or with direct composite restoration. International Endodontic Journal. Int Endod J, 2009 42(5), 401-405.

[20] Torabzadeh, H., Ghassemi, A., Sanei, M., Razmavar, S. Sheikh-Al-Eslamian, S. M. The influence of composite thickness with or without fibers on fracture resistance of direct restorations in endodontically treated teeth. Iranian Endodontic Journal. Iranian Association of Endodontics, 2014, 9(3), 215-219.

[21] Soares, P. V., Santos-Filho, P. C. F., Martins, L. R. M. \& Soares, C. J.Influence of restorative technique on the biomechanical behavior of endodontically treated maxillary premolars. Part I: Fracture resistance and fracture mode. Journal of Prosthetic Dentistry. J Prosthet Dent, 2008 99(1), 30-37.

[22] Belli, S., Eraslan, O. \& Eskitascioglu, G. Direct Restoration of Endodontically Treated Teeth: a Brief Summary of Materials and Techniques. Current Oral Health Reports, 2015 2(4), 182189.

[23] Mannocci, F. , Cowie, J. Restoration of endodontically treated teeth. British Dental Journal. Nature Publishing Group, 2014216 (6), 341-346.

[24] Shu, X., Mai, Q.-Q., Blatz, M., Price, R., Wang, X.-D., Zhao, K. Direct and Indirect Restorations for Endodontically Treated Teeth: A Systematic Review and Meta-analysis, IAAD 2017 Consensus Conference Paper. The journal of adhesive dentistry, 2018 20(3), 183-194.

[25] Von Stein-Lausnitz, M., Mehnert, A., Bruhnke, M., Sterzenbach, G., Rosentritt, M., Spies, B. C., Bitter, K. \& Naumann, M. Direct or Indirect Restoration of Endodontically Treated Maxillary Central Incisors with Class III Defects? Composite vs Veneer or Crown Restoration. The journal of adhesive dentistry, 2018 20(6), 519-526.

[26] Saridag, S., Pekkan, G.Esthetic Restoration of Eroded Teeth Using Porcelain Laminate Veneers With Different Preparation Techniques: Case Report. Atatürk Üniversitesi Diş Hekimliği Fakültesi Dergisi, 2011 (3), 241-244.

[27] Pippin, D. J., Mixson, J. M. \& Soldan-Els, A. P. Clinical evaluation of restored maxillary incisors: veneers vs. PFM crowns. Journal of the American Dental Association (1939).,1995 126(11), 1523-1529.

[28] Bagis, B., Aydoğan, E. , Bagis, Y. H. Direct Restorative Treatment of Missing Maxillary Laterals with Composite Laminate Veneer: A
Case Report. The Open Dentistry Journal. 2008 2(1), 93-95.

[29] Alothman, Y., Bamasoud, M. S, The success of dental veneers according to preparation design and material type. Open Access Macedonian Journal of Medical Sciences, 2018 6(12), 2402-2408

[30] Shillingburg HT, Hobo S, Whitsett LD, Jacobi $\mathrm{R}$ and Brackett SE. Fundamental of Fixed Prosthodontics, 3rd edn. 1997.

[31] Ram, H. K., Shah, R. J. \& Agrawal, H. S., Evaluation of three different tooth preparation techniques for metal ceramic crowns by comparing preparation depths: An in vitro study. Journal of Indian Prosthodontist Society,2015 15(2), 162-167.

[32] Pjetursson, B. E., Sailer, I., Zwahlen, M. \& Hämmerle, C. H. F., A systematic review of the survival and complication rates of all-ceramic and metal-ceramic reconstructions after an observation period of at least 3 years. Part I: Single crowns. Clinical Oral Implants Research,2007a ,18(SUPPL. 3), 73-85.

[33] Badran, N., Kader, S. A. \& Alabbassy, F. Effect of Incisal Porcelain Veneering Thickness on the Fracture Resistance of CAD / CAM Zirconia All-Ceramic Anterior Crowns., 2019.

[34] Zarone, Fernando \& Russo, Simona, Sorrentino, Roberto. From Porcelain-Fused-toMetal to Zirconia: Clinical and Experimental Considerations. Dental materials : official publication of the Academy of Dental Materials.2011 27. 83-96

[35] Veselinović, Valentina \& Todorović, Aleksandar \& Lisjak, Dejan \& Lazic, Vojkan, Restoring endodontically treated teeth with allceramic endo-crowns - case report., Stomatološki Glasnik Srbije.2008 55.

[36] Danaei, S. M., Safavi, A., Roeinpeikar, S. M. M., Oshagh, M., Iranpour, S. \& Omidekhoda, M. Ion release from orthodontic brackets in 3 mouthwashes: An in-vitro study. American Journal of Orthodontics and Dentofacial Orthopedics. American Association of Orthodontists, 2011 139(6), 730-734.

[37] Zhang, X., Wei, L. C., Wu, B., Yu, L. Y., Wang, X. P. \& Liu, Y. A comparative analysis of metal allergens associated with dental alloy prostheses and the expression of HLA-DR in gingival tissue. Molecular Medicine Reports, 2016, 13(1), 91-98.

[38] Pjetursson, B. E., Sailer, I., Zwahlen, M. \& Hämmerle, C. H. F. A systematic review of the survival and complication rates of all-ceramic and metal-ceramic reconstructions after an observation period of at least 3 years. Part I: 
Review Article: Different Types of Coronal Restoration for Endodontically Treated Anterior Teeth: Treatment Recommendation

Single crowns. Clinical Oral Implants Research, 2007b, 73-85.

[39] Carlos, R. B., Thomas Nainan, M., Pradhan, S., Roshni Sharma, Benjamin, S., \& Rose, R. (2013). Restoration of endodontically treated molars using all ceramic endocrowns. Case reports in dentistry, 2013, 210763.

[40] Hamdy, A. Effect of Full Coverage , Endocrowns, Onlays, Inlays Restorations on Fracture Resistance of Endodontically Treated Molars. Journal of Dental and Oral Health, 2015 1(5), 1-5.

[41] Aurélio, I. L., Fraga, S., Rippe, M. P. \& Valandro, L. F. Are posts necessary for the restoration of root filled teeth with limited tissue loss? A structured review of laboratory and clinical studies. International Endodontic Journal, (2015), 827-835.

[42] Naumann M, Koelpin M, Beuer F, MeyerLueckel H (2012) 10-year survival evaluation for glass-fiber-supported postendodontic restoration: a prospective observational clinical study. Journal of Endodontics 2012, 38, 432-5

[43] CHEUNG, W. (2005) A review of the management of endodontically treated teeth. The Journal of the American Dental Association, 2005 136(5), 611-619.

[44] Pruthi, V., Talwar, S., Nawal, R., Pruthi, P., Choudhary, S. \& Yadav, S. (2018) Evaluation of retention and fracture resistance of different fiber reinforced posts: An in vitro study. Journal of Conservative Dentistry, 2018, 21(2), 157.

[45] Schwartz, R. S. \& Robbins, J. W. Post Placement and Restoration of Endodontically Treated Teeth: A Literature Review. 2004.

[46] Biacchi, G. R. \& Basting, R. T. (2012) Comparison of fracture strength of endocrowns and glass fiber post-retained conventional crowns. Operative Dentistry, 2012 37(2), 130136.

[47] Ferrari M, Vichi A, García-Godoy F. Clinical evaluation of fiber-reinforced epoxy resin posts and cast post and cores. Am J Dent. 2000;13(Spec No):15B-18B.

[48] Ferrari M, Vichi A, Fadda GM et al. (2012) A randomized controlled trial of endodontically treated and restored premolars. Journal of Dental Research 91(Suppl 7), 72S-8S.

[49] Mangold JT, Kern M, Influence of glass-fiber posts on the fracture resistance and failure pattern of endodontically treated premolars with varying substances loss: an in vitro study, J Prosthetic Dentistry, 2011, 105: 387-393.

[50] Valdivia AD, Raposo LH, Simamoto-Junior PC, Novais VR, Soares CJ, The effect of fiber post presence and restorative technique on the biomechanical behavior of endodontically treated maxillary incisors: an in vitro study. Journal of Prosthetic Dentistry, 2012, 108, 147-57.

[51] Bateman, G., Ricketts, D. N. J. \& Saunders, W. P. Fibre-based post systems: A review. British Dental Journal. Br Dent J,2003 43-48.

[52] Bakirtzoglou, E., Kamalakidis, S. N., Pissiotis, A. L. \& Michalakis, K. In vitro assessment of retention and resistance failure loads of complete coverage restorations made for anterior maxillary teeth restored with two different cast post and core designs. Journal of Clinical and Experimental Dentistry, 2019, 11(3), e225-e230.

[53] Landys Borén, D., Jonasson, P. \& Kvist, T. (2015) Long-term survival of endodontically treated teeth at a public dental specialist clinic. Journal of Endodontics. 2015, 41(2), 176-181.

[54] Bhagat, A., Mittal, L., Mogla, S., Kaur, T., Dheeraj, M. \& Marwah, G. (2017) Impact of root dentin thickness on the in vitro compressive strength of teeth treated with recent post and core systems. Journal of Contemporary Dental Practice. 2017, 18(11), 1065-1070.

[55] Rosenstiel SF, Land MF and Fujimoto J (2001). Contemporary Fixed Prosthodontics, 3rd edn. St. Louis, Missouri: 2001

[56] Standlee, J. P., Caputo, A. A. \& Hanson, E. C. (1978) Retention of endodontic dowels: Effects of cement, dowel length, diameter, and design. The Journal of Prosthetic Dentistry. J Prosthet Dent,1978 39(4), 401-405.

[57] Bergman, B. \& Lundquist, P. (1989) With Cast. Statistics, 61(January)

[58] Seefeld, F., Wenz, H. J., Ludwig, K. \& Kern, M. Resistance to fracture and structural characteristics of different fiber reinforced post systems. Dental Materials, 2007 23(3), 265-271.

[59] King, P.A., Setchell D.J., Rees J.S., Clinical evaluation of a carbon fibre reinforced carbon endodontic post, Journal of Oral Rehabilitation, 2003 30: 785-789

[60] Fredriksson M., Astback J., Pamenius M. et al , A retrospective study of 236 patients with teeth restored by carbon fiber-reinforced epoxy resin posts, The Journal of Prosthetic dentistry, 1998: 80(2), 151-157

[61] Rosentritt, M., Fürer, C., Behr, M., Lang, R. \& Handel, G. (2000) Comparison of in vitro fracture strength of metallic and tooth-coloured posts and cores. Journal of Oral Rehabilitation. 2000, 595-601. 
Review Article: Different Types of Coronal Restoration for Endodontically Treated Anterior Teeth: Treatment Recommendation

[62] Guragain, M., Mathema, S. \& Rokaya, D. (2020) Evaluation of Fracture Resistance and Sites of Failure of Different Dowel Core Restorations: An In-Vitro Study. The Open
Dentistry Journal., 2020 13(1), 454-461.

[63] Eliyas, S., Jalili, J. \& Martin, N. (2015) Restoration of the root canal treated tooth. British Dental Journal.,2015 218(2), 53-62.

Citation: Samsudin Nurulaqmar-Iwani, "Review Article: Different Types of Coronal Restoration for Endodontically Treated Anterior Teeth: Treatment Recommendation”, International Journal of Research Studies in Medical and Health Sciences. 2020; 5(8): 26-35.

Copyright: () 2020 Samsudin Nurulaqmar-Iwani, This is an open-access article distributed under the terms of the Creative Commons Attribution License, which permits unrestricted use, distribution, and reproduction in any medium, provided the original author and source are credited. 